Artículo científico

Volumen 31(2):433-444. Mayo-agosto, 2020

e-ISSN 2215-3608, doi:10.15517/am.v31i2.38308

http://www.revistas.ucr.ac.cr/index.php/agromeso

\title{
Estudio molecular de seis cepas de Cochliomyia hominivorax (Coquerel) (Diptera: Calliphoridae) y Cochliomyia macellaria ${ }^{1}$
}

\section{Molecular study of six strains of Cochliomyia hominivorax (Coquerel) (Diptera: Calliphoridae) and Cochliomyia macellaria}

\author{
Claudia Elizabeth Toledo-Perdomo², Steven R. Skoda ${ }^{3}$
}

1 Recepción: 16 de julio, 2019. Aceptación: 5 de diciembre, 2019. Este trabajo formó parte del proyecto de investigación "Caracterización molecular de 6 cepas del gusano barrenador del ganado Cochliomyia hominivorax (Coquerel) y de la especie Cochliomyia macellaria (Fabricius) (Diptera:Calliphoridae)", financiado por el Agriculture Research Service (ARS-USDA).

2 Universidad de San Carlos de Guatemala, Guatemala. toledo.perdomo@gmail.com (https://orcid.org/0000-0003-2281-3216).

3 United States Department of Agriculture (USDA), Agriculture Research Service (ARS), Unidad de Investigación de Plagas de Artrópodos del Ganado. Kerrville, Texas, Estados Unidos. Retirado. srskoda06@hotmail.com (https://orcid.org/0000-0002-6162-3450).

\section{Resumen}

Introducción. El gusano barrenador del ganado, Cochliomyia hominivorax (Coquerel), es una plaga de importancia económica para animales de sangre caliente, principalmente el ganado vacuno. Objetivo. Caracterizar molecularmente seis cepas de Cochliomyia hominivorax (Coquerel) y la especie Cochliomyia macellaria, por medio de las secuencias del mtADN. Materiales y métodos. El estudio se realizó durante los años 2006 y 2007, utilizando seis cepas de colonias procedentes de México, Panamá y Costa Rica, ubicadas en el Laboratorio de Biología Molecular del Instituto Smithsonian de Investigaciones Tropicales, Panamá. Se optimizaron tres cebadores de seis que fueron evaluados, por medio del método de secuenciación cíclica. Para establecer las relaciones filogenéticas entre las cepas se realizaron los análisis de Parsimonia, NJ (Neighbor-Joining), Máxima Verosimilitud y Bayesiano. Para C. macellaria se evaluaron tres cebadores que fueron utilizados para $C$. hominivorax. Resultados. Se obtuvieron las regiones del genoma mitocondrial NADH4-tRNA-NADH5. Todos los análisis mostraron la misma topología formando cuatro clados definidos. El primero formado por las cepas de Oaxaca y Quintana Roo, el segundo por las cepas de Chiapas, el tercero por las cepas de Costa Rica y Panamá y el cuarto por la población de Brasil, obtenida de GenBank. En C. macellaria dos cebadores lograron amplificar la región NADH4 y uno la región NADH5. Conclusión. Las amplificaciones obtenidas en esta investigación aportan información para continuar con los estudios moleculares entre las especies de C. macellaria y C. hominivorax; también para identificar el origen geográfico de las cepas.

Palabras clave: vigilancia epidemiológica, ADN mitocondrial, miasis, filogenia.

\begin{abstract}
Introduction. The cattle borer worm, Cochliomyia hominivorax (Coquerel), is an economically important pest for warm-blooded animals, mainly cattle. Objective. Molecularly characterize six strains of Cochliomyia hominivorax
\end{abstract}


(Coquerel) and the Cochliomyia macellaria species using the mtDNA sequences. Materials and methods. The study was conducted during 2006 and 2007, using six strains from colonies of Mexico, Panama, and Costa Rica, located in the Molecular Biology Laboratory of the Smithsonian Tropical Research Institute, Panama. Three out of six primers were optimized and evaluated, using the cyclic sequencing method. Parsimonia, NJ (Neighbor-Joining), Maximum Likelihood, and Bayesian analyzes were performed to establish the phylogenetic relationships between the strains. Three primers used for $C$. hominivorax were evaluated for $C$. macellaria. Results. The regions of the mitochondrial genome NADH4-tRNA-NADH5 were obtained. All the analyzes showed the same topology forming four defined clades. The first formed by the strains from Oaxaca and Quintana Roo, the second by the strains from Chiapas, the third by the strains from Costa Rica and Panama, and the fourth by the population from Brazil, obtained from GenBank. In C. macellaria two primers were able to amplify the NADH4 region and one NADH5 region. Conclusion. The amplifications obtained in this research provide information to continue the molecular studies between the species of C. macellaria and C. hominivorax; also to identify the geographical origin of the strains.

Keywords: epidemiological monitoring, mitochondrial DNA, myiasis, phylogeny.

\section{Introducción}

El gusano barrenador del ganado (GBG), Cochliomyia hominivorax (Coquerel) es una plaga de importancia económica para animales de sangre caliente, principalmente el ganado vacuno, que también afecta a los humanos. Es considerada una las plagas más importantes del ganado en el hemisferio occidental (Skoda et al., 2002; Visciarelli et al., 2003; Ferreira-do-Nascimento et al., 2005; De-la-Ossa et al., 2009).

En 1959 el Departamento de Agricultura de los Estados Unidos (USDA) inició el programa de erradicación del gusano barrenador del ganado en ese país y en 1966 fue declarado libre de la plaga. Los trabajos de erradicación continuaron desde México hasta Panamá, declarando la zona libre del GBG en el año 2007. Sin embargo, en el año 2016, un nuevo brote de GBG fue detectado en Florida, USA. Con base en un trabajo en conjunto del Servicio de Inspección de Sanidad Animal y Vegetal del USDA, el Servicio de Investigación Agrícola (ARS), el Estado de Florida, el Servicio de Pesca y Vida Silvestre y los funcionarios locales, que respondieron al brote, en marzo de 2017 fue declarada nuevamente zona libre de GBG (Skoda et al., 2018).

En la actualidad el GBG también se encuentra presente en algunos países del Caribe y en América del Sur, exceptuando a Chile (Reck et al., 2014). Esta situación continúa poniendo en riesgo nuevas infestaciones en los países donde la plaga ya ha sido erradicada.

Estudios realizados de C. hominivorax y su relación con otros agentes causantes de miasis en Ecuador, indican que el ataque primario es causado por C. hominivorax, seguido de Cochliomyia macellaria (Fabricius), pero en tasas de infestación más bajas (Arteaga et al., 2012).

Una de las actividades importantes del programa de erradicación del GBG es su correcta identificación. En estudios realizados se han encontrado diferencias morfológicas entre individuos de distintas poblaciones como la variación del color de cuerpo, ojos, anormalidades de la venación de las alas y otras diferencias morfológicas que dificultan su correcta identificación (Taylor y Martínez, 1986). El estudio de los genomas mitocondriales (mtADN) se ha venido incrementando, han incorporado nuevos marcadores con mayor sensibilidad, debido a que estos aportan fácilmente información genética, detectando cambios en el genotipo del espécimen, que puede ser usada en investigaciones moleculares, de evolución e identificación de poblaciones (Becerra y Paredes, 2000).

Estudios realizados por Litjens et al. (2001), demostraron que en el GBG basado en el análisis específico en las regiones mtDNA, se facilita el potencial de acercamiento para la identificación taxonómica y relaciones entre poblaciones. 
Se han realizado estudios genéticos de las especies C. hominovorax y Glossina spp. (mosca tse-tsé) que afectan al ganado, enfocados en la distribución de las poblaciones (Feldmann y Ready, 2014). Además de estudios para establecer diferencias ente los géneros Cochliomyia y Chrysomya mediante técnicas moleculares (Cardoso et al., 2014). También se han realizado estudios de selección y validación de genes por el método PCR en tiempo real de las especies C. hominivorax, C. macellaria y C. albiceps, se estudiaron tres marcadores del mtADN de $C$. hominivorax y ocho loci microsatélites nucleares para conocer la diversidad genética de la región amazónica de Brasil (Mastrangelo et al., 2014), en estos estudios establecieron una diversidad de las nueve poblaciones del GBG; se identificaron 46 haplotipos, de los cuales 39 fueron nuevos en la región.

La especie C. macellaria es muy común en el neotrópico de América, su distribución geográfica se traslapa con el de C. hominivorax, además, morfológicamente son muy similares. C. macellaria es considerada como una plaga secundaria de miasis en el ganado, alimentándose principalmente de tejidos muertos (Litjens et al., 2001; Skoda et al., 2002). Tiene un alto parecido morfológico entre los adultos de ambas especies y en los primeros estadios larvales, y en determinado momento resulta muy difícil identificarlas, representando un problema para el programa de erradicación del GBG. Debido a que las liberaciones de moscas estériles dependerán de la correcta identificación de $C$. hominivorax, es importante aportar información que contribuya para los estudios moleculares entre ambas especies.

El objetivo de este trabajo fue el estudio molecular de seis cepas de Cochliomyia hominivorax y la especie Cochliomyia macellaria (Fabricius) por medio de las secuencias del mtADN.

\section{Materiales y métodos}

El estudio se realizó durante los años 2006 y 2007, en el Laboratorio de Biología Molecular del Instituto Smithsonian de Investigaciones Tropicales en Panamá. Se utilizaron especímenes de seis cepas de C. hominivorax y la especie $C$. macellaria. Las cepas de $C$. hominivorax, se colectaron en México, Costa Rica y Panamá, antes de su erradicación en cada país (en México antes de 1987, en Costa Rica antes de 1995 y Panamá en el año 1995), con estas colectas se estableció el pie de cría por el personal del Servicio de Investigación Agrícola (ARS, por sus siglas en inglés), del Gobierno de Estados Unidos, donde hasta la fecha se mantienen en el Laboratorio de la Comisión Panamá - Estados Unidos para la Erradicación y Prevención del Gusano Barrenador del Ganado (COPEG), en Panamá (Cuadro 1).

La colecta de C. macellaria se realizó en campos de área pecuaria en Pacora, Panamá. Las trampas se colocaron al lado de los cercos de los potreros de ganado bovino, las cuales consistieron de bandejas con hígado de pollo como atrayente, las moscas adultas se capturaron con red entomológica, los especímenes colectados se colocaron en viales con etanol al $95 \%$ y se almacenaron a una temperatura de $20{ }^{\circ} \mathrm{C}$.

Todos los procedimientos moleculares se realizaron en el laboratorio del Instituto Smithsoniano de Investigaciones Tropicales (STRI), Panamá. Para la extracción del mtADN se empleó la metodología de Malliphan et al. (2006), con base en el método CTAB (bromuro de hexadecyltrimethilmeammonium) como extracción inicial. Se utilizaron diez moscas por cada cepa de $C$. hominivorax y diez moscas de la especie $C$. macellaria. Se utilizó el tórax de cada mosca para la extracción de mtADN de cada espécimen, estos fueron colocados en tubos de 1,5 ml. El tórax se maceró y se le aplicó la solución de $500 \mu \mathrm{l} 2 \mathrm{X}$ CTAB, luego se agregó $10 \mu 1$ de proteinasa $\mathrm{K}\left(20 \mu \mathrm{g} \mu 1^{-}\right.$ $\left.{ }^{1}\right)$ y se incubó a $55^{\circ} \mathrm{C}$ durante toda la noche. La mezcla se lavó con $500 \mu 1$ de fenol:cloroformo:alcohol isoamílico (PCI) por $5 \mathrm{~min}$, se centrifugó a $14000 \mathrm{rpm}$ por $3 \mathrm{~min}$, el sobrenadante se extrajo con $500 \mu 1$ de cloroformo:alcohol isoamilico (24:1), se mezcló por $5 \mathrm{~min}$ y se centrifugó a $14000 \mathrm{rpm}$ por $3 \mathrm{~min}$. El sobrenadante nuevamente se extrajo con $500 \mu 1$ de cloroformo: alcohol isoamílico (24:1), se mezcló por 5 min, y se centrifugó a $14000 \mathrm{rpm}$ por 3 min. Al sobrenadante se agregó $1000 \mu 1$ de etanol al $100 \%$, se dejó precipitar durante toda la noche a -20 
Cuadro 1. Principales características de las cepas del gusano barrenador del ganado (C. hominivorax) colectadas y criadas por Agriculture Research Service, su procedencia, y la especie C. macellaria. 2007.

Table 1. Main characteristics of the cattle borer worm strains (C. hominivorax) collected and bred by Agriculture Research Service and its origin, and the C. macellaria species. 2007.

\begin{tabular}{|c|c|c|c|c|c|c|}
\hline Especie & Cepa & Lugar de Procedencia & $\begin{array}{l}\text { Características } \\
\text { morfológicas }\end{array}$ & Latitud & Longitud & Año de colecta \\
\hline C. hominivorax & LH & Oaxaca, México & Ojos amarillos & 17,05 & $-96,7167$ & 1984 \\
\hline C. hominivorax & P-95 & $\begin{array}{l}\text { Gamboa, ciudad de } \\
\text { Panamá, Panamá }\end{array}$ & Tipo salvaje & 9,3333 & $-82,25$ & 1995 \\
\hline C. hominivorax & $\mathrm{CECH}$ & $\begin{array}{l}\text { Chetumal, Quintana } \\
\text { Roo, México }\end{array}$ & Ojos rojos & 19,6667 & $-88,5$ & 1985 \\
\hline C. hominivorax & $\mathrm{PA}-34$ & Chiapas, México & Ojos anaranjados & 16,5 & $-92,5$ & 1983 \\
\hline C. hominivorax & CR-92 & $\begin{array}{c}\text { Oeste de San José, Costa } \\
\text { Rica }\end{array}$ & Tipo salvaje & 10 & $-84,25$ & 1992 \\
\hline C. hominivorax & Limón & $\begin{array}{c}\text { Palenque, Chiapas, } \\
\text { México }\end{array}$ & Ojos verdes claro & 16.5 & $-92,5$ & 1983 \\
\hline C. macellaria & -- & Pacora, Panamá & --- & 8,41667 & $-81,67$ & 2006 \\
\hline
\end{tabular}

${ }^{\circ} \mathrm{C}$. Posteriormente, se centrifugó a $12000 \mathrm{rpm}$ durante 45 min a $4{ }^{\circ} \mathrm{C}$ para formar el botón del ADN, luego se agregó $1000 \mu \mathrm{l}$ de etanol al $70 \%$ a $-20{ }^{\circ} \mathrm{C}$ y se centrifugó a $14000 \mathrm{rpm}$ por $15 \mathrm{~min}$. El etanol se decantó y el tubo se incubó a $55^{\circ} \mathrm{C}$. Finalmente, se agregó $100 \mu 1$ de buffer TE para resuspender el ADN, mismo que se verificó por medio de electroforesis.

Para la amplificación de la reacción en cadena de la polimerasa (PCR) los cebadores (= primers) fueron apareados y utilizados en la amplificación del mtADN. Los cebadores utilizados y el protocolo de PCR que se estableció como punto de partida para iniciar la investigación fue el propuesto por Malliphan et al. (2006). Fue necesario optimizar los protocolos para cada par de cebadores. Se evaluaron seis pares de cebadores (Cuadro 2).

Las regiones que amplifican los primers son: 7F,7R $=1 \mathrm{NADH} 4$ (nicotinamida-adenina-dinucleótido (NAD) reducida), 8F,8R = comprende parte de las regiones NADH4 y NADH5 y el ARN parte del gen, ubicado entre las dos regiones mencionadas; 9F,9R= comprende la región NADH5.

Las reacciones de PCR fueron conducidas en una mezcla de PCR de $25 \mu 1: 2 \mu \mathrm{g}$ de ADN, 2,5 $\mu 1$ de Quiagen

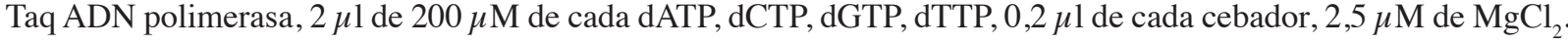
La mezcla de PCR se colocó en un termociclador.

Se realizaron pruebas con distintas cantidades de $\mathrm{MgCl}_{2}$ y Quiagen Taq para optimizar los cebadores. Las condiciones de temperatura empleadas fueron: temperatura inicial de $94{ }^{\circ} \mathrm{C}$ por $3 \mathrm{~min}, 94{ }^{\circ} \mathrm{C}$ por $1 \mathrm{~min}, 30 \mathrm{~s}$ a 50 ${ }^{\circ} \mathrm{C}-60{ }^{\circ} \mathrm{C}$, este rango de temperatura fue evaluado para encontrar la temperatura ideal para el cebador, $72{ }^{\circ} \mathrm{C}$ por 1 min (35 ciclos), finalmente, 2 min a $72{ }^{\circ} \mathrm{C}$.

Para la reacción en cadena de la polimerasa en la especie $C$. macellaria se evaluaron tres pares de cebadores: Primer 7F/7R (N5-J-7660/N5-N-8853), Primer 8F/8R (N5-J-8621/ N4-N-9676) y Primer 9F/9R (N4-J-9580/ NL-N-10740), descritos en la Cuadro 2. Con las regiones amplificadas de cada par de cebadores se realizó la secuenciación en ciclo para obtener las secuencias de cada una de las regiones amplificadas $C$. hominivorax y $C$. macellaria.

La purificación del DNA se basó en la metodología de Lessios et al. (1996), el producto de la PCR se colocó en un gel de agarosa con temperatura de derretimiento bajo una concentración de 2,0 \%. El producto de PCR corrió 
Cuadro 2. Código, nombre, secuencia y tamaño del fragmento de cada uno de los cebadores (= primers) empleados en la evaluación para Cochliomyia hominivorax. Panamá, 2007.

Table 2. Code, name, sequence, and fragment size of each of the primers (= primers) used in the evaluation for Cochliomyia hominivorax. Panamá, 2007.

\begin{tabular}{lccc}
\hline CóDIGO & NOMBRE & SECUENCIAS & TAMAÑ $($ bp) \\
\hline Primer 3F & N2-J-1480 & TACAATTTATCGCCTAAACTTCAGCC & 2,450 \\
Primer 3R & C2-N-3793 & GAGACCATTACTTGCTTTCAGTCATCT & \\
Primer 4F & C2-J-3662 & GGTCAATGTTCAGAAATTTGTGG & 2,320 \\
Primer 4R & N3-N-5942 & TGATTTCATTCATGATATAAGTCC & \\
Primer 7F & N5-J-7660 & TTCTGATCATCCCTGATC & 1,194 \\
Primer 7R & N5-N-8853 & GTAAAATCTTATAATGCTGG & \\
Primer 8F & N5-J-8621 & GCTATAGCAGCTGGCAATCAAG & \multirow{2}{*}{, 076} \\
Primer 8R & N4-N-9676 & CTTATGAACGGATGGGGAGTC & \multirow{2}{*}{1,161} \\
Primer 9F & N4-J-9580 & TAGGAGGAGCAGCCATATTTGGC & \\
Primer 9R & NL-N-10740 & GAAGGTCTTGGGCTTTCT & 1,148 \\
Primer 10F & NL-J-10725 & AAGCCCAAGACCTTC & \\
Primer 10R & CB-N-11872 & GATGCACCATTGGCATGT & \\
& & &
\end{tabular}

a $98 \mathrm{~V}$ en la cámara de electroforesis y, posteriormente se cortaron las bandas. Estas se colocaron en tubos de 1,5 $\mu \mathrm{l}$ y se llevaron a la termocicladora en donde permanecieron por $5 \mathrm{~min}$ a $70^{\circ} \mathrm{C}$. Luego, se colocaron a $45^{\circ} \mathrm{C}$ por $15 \mathrm{~min}$. Se les agregó a cada tubo $1,2 \mu \mathrm{l}$ de gelasa y se dejaron a $45^{\circ} \mathrm{C}$.

La secuenciación en ciclo se realizó tomando como base los protocolos de Lessios et al. (1996): $2 \mu \mathrm{l}$ de agua doble destilada, $3 \mu \mathrm{l}$ de buffer BD 5X, $1 \mu \mathrm{l}$ del cebador "F"/"R", $1 \mu \mathrm{l}$ de big dye y $3 \mu \mathrm{l}$ de la banda cortada y tratada con gelasa. Luego la mezcla se centrifugó por $30 \mathrm{~s}$. Después de centrifugada se llevaron al termociclador PTC-200 utilizando el programa CS3 100, el cual consistió en una temperatura inicial de $96^{\circ} \mathrm{C}$ por un min, seguido de $96{ }^{\circ} \mathrm{C}$ por $10 \mathrm{~s}, 50^{\circ} \mathrm{C}$ por $5 \mathrm{~s}, 60^{\circ} \mathrm{C}$ por $4 \mathrm{~min}$ y, finalmente 24 ciclos desde el segundo paso. Al terminar este proceso, a los tubos se les agregó $10 \mu \mathrm{l}$ de agua doblemente destilada.

Se prepararon columnas con Sephadex G-50. A cada columna se le agregó la reacción de secuenciación, se centrifugaron a $3600 \mathrm{rpm}$ por 3 min y se dejaron secar. Posteriormente, se les agregó $10 \mu 1$ de diformamida y se corrieron las secuencias en una secuenciadora con una lectura del fragmento del 98,5\% de exactitud.

\section{Procesamiento y análisis de los datos}

Para el estudio filogenético se realizaron los análisis de Neighbor Joining (NJ) y de parsimonia con los genes mitocondriales, usando para ambos el PAUP*4.0b10 (Altivez). Posteriormente, se realizó en análisis de partición también el PAUP*4.0b10 (Altivez). Luego se realizaron los análisis para estos mismos genes mitocondriales de máxima verosimilitud (Maximum Likelihood -ML-). Se realizó un análisis en MrModeltest para luego realizar el análisis Bayesiano, estos permitieron conducir los estudios filogenéticos en la investigación para cada uno de los genes mitocondriales independientemente y en consenso, para luego verificar la congruencia entre la topología de los árboles filogenéticos.

El análisis MP se realizó con base en búsquedas heurísticas con intercambio de ramas (TBR). El análisis de Bootstrap (1000 réplicas) se utilizó para conocer el soporte de las ramas. Para el análisis ML se utilizó Modeltest 
3.6 para elegir el mejor modelo de sustitución en los datos, utilizando el criterio Herarquical (HLRT), y como criterio estadístico entre los modelos se eligió AKAIKE (AIC) y a TRN+I como modelo evolutivo. El análisis filogenético Bayesiano fue conducido utilizando MrBayes 3.1. En todos estos análisis se buscó las relaciones entre las cepas. Los árboles filogenéticos obtenidos de estos análisis fueron editados en el programa Canvas 9TM.

Para los árboles filogenéticos de $C$. hominivorax se empleó como grupo externo (outgruop) a la especie Chrysomya putoria (Junqueira et al., 2004), debido a que molecularmente es la especie más cercana a $C$. hominivorax. Las secuencias de C. putoria fueron de la misma región (NADH4, tRNA, NADH5) amplificada para C. hominivorax de Brasil (Lessinger et al., 2000), las cuales fueron obtenidas del GenBank.

\section{Resultados}

Se logró la amplificación del mtADN de C. hominivorax con los cebadores: 7, 8 y 9. Para $C$. macellaria se lograron optimizar los cebadores 8 y 9 (Cuadro 3 ).

Cuadro 3. Protocolos optimizados de cada cebador, para las especies C. hominivorax y C. macellaria. Panamá, 2007.

Table 3. Optimized protocols of each primer for the C. hominivorax and C. macellaria. species. Panamá, 2007.

\begin{tabular}{lccccc}
\hline & & C. hominivorax & & \multicolumn{2}{c}{ C. macellaria } \\
\cline { 2 - 6 } & Cebador 7 & Cebador 8 & Cebador 9 & Cebador 8 & Cebador 9 \\
\hline Buffer & $1 \mathrm{X}$ & $1 \mathrm{X}$ & $1 \mathrm{X}$ & $1 \mathrm{X}$ & $1 \mathrm{X}$ \\
MgCl2 & $2 \mathrm{mM}$ & $1,25 \mathrm{mM}$ & $3 \mathrm{mM}$ & $1,25 \mathrm{mM}$ & $2 \mathrm{Mm}$ \\
DNTPs & $0,2 \mathrm{mM}$ & $0,2 \mathrm{mM}$ & $0,2 \mathrm{mM}$ & $0,2 \mathrm{mM}$ & $0,2 \mathrm{mM}$ \\
Cebador(=primer) F/R & $0,5 \mathrm{Mm}$ & $0,5 \mathrm{Mm}$ & $0,5 \mathrm{Mm}$ & $0,5 \mathrm{Mm}$ & $0,5 \mathrm{Mm}$ \\
Qiagen Taq & $1 \mathrm{U} \mu^{-1}$ & $1 \mathrm{U} \mu^{-1}$ & $1 \mathrm{U} \mu^{-1}$ & $1 \mathrm{U} \mu^{-1}$ & $2 \mathrm{U} \mu^{-1}$ \\
\hline
\end{tabular}

Los tamaños de las regiones amplificadas fueron para el primer 7F,7R $=1,110 \mathrm{pb}$ (NADH4) primer 8F,8R = $1,000 \mathrm{pb}$ (NADH4 y NADH5 y parte del gen el ARN ubicado entre las dos regiones mencionadas), primer 9F,9R= $1,038 \mathrm{pb}$ (NADH5). Para un total de 3,148 pb en la región completa amplificada (NADH4, tRNA, NADH5).

De los cebadores evaluados para la especie C. macellaria, se optimizaron los cebadores 8F (N5-J-8621), 8R (N4-N-9676) y 9F (N4-J-9580), 9R (NL-N-10740), comprendiendo las regiones NADH4 y NADH5, parte del gen de ARN ubicado entre las dos regiones mencionadas y NADH5 completa.

Debido a que los cebadores 8 y 9 fueron optimizados para las especies $C$. hominvorax y $C$. macellaria, estos pueden aportar información para futuros estudios genéticos entre ambas especies (Cuadros 3 y 4).

Todos los análisis realizados (NJ, Parsimonia, Máxima Verosimilitud, Bayesiano) mostraron la misma tendencia, los árboles que se presentan en la investigación fueron los corridos con el análisis Bayesiano, debido a que este proporciona al mismo tiempo un árbol filogenético con soporte (Figura 1).

En la región NADH5 y parte del gen de tRNA (Primer 7) se mostró un nodo basal definido, de donde nacieron cuatro clados, formando una politomía. El primer clado formado por las cepas de Quintana Roo (CECH) y Oaxaca (LH), el segundo clado, por las cepas de Chiapas (PA-34 y Limón), el tercer clado integrado por las cepas de Panamá (P95) y Costa Rica (CR-92) y finalmente, el cuarto clado comprendido únicamente por la población de Brasil.

El primer 8 amplificó una pequeña región de los genes NADH4 y NADH5, y la región completa del tRNA (Primer 8), que se encuentra ubicado entre los dos genes anteriormente mencionados, amplificó la región con 
Toledo-Perdonmo y Skoda: Caracterización molecular de seis cepas de Cochliomyia hominivorax

Cuadro 4. Secuencias obtenidas de C. macellaria. Panamá, 2007.

Table 4. Sequences obtained from C. macellaria. Panamá, 2007.

\section{Cebador 8}

GAATTAATTTTATACCTTCAATAGCATTATGATGATTTTTATTAAGATCAGCTAATATGGCTGCTCCTCCTACATTAAATTTATTAGGA GAAATTTCTTTAATTAATAGAATTGTTAGATGATCTTGAGTTTCTATATTTATGTTATCTTTATTATCTTTTTTTAGAGCTGCTTATACTTTATATTTATATGCTTATAGTCAACATGGAAAGATTTTTTCAGGAGCTTATTCATTTAGAGGAGGATCAGTTCGAGAATTTTTACTTTTATTTTTACATTGATTTCCTTTAAATTTATTAATTTTAAAGGGAGATATGTGTATATTATGATTATGTTTAAATAGTTTAATTAAAATATTGATTTGTGGTGTCAATGATAAGAAGTTTTCTTTTTAAACCGTGAAATATTTATCAATTTGTACAATTAGATTTGTAAGTTTATTTTTTTTTAGTTTATCTTCTTTTTTAATAGGAATGATTTTTATTATGAATGATTATAGAATTTTTATTGAATGAGAAGTAGTGTCTATAAATTCAATAAATATTGTTATAACTTTATTATTAGATTGAATAAGATTAATTTTTATATCTTTTGTTTTAATAATTTCTTCTTTAGTTATTTTTTATAGAAAGGAATATATAGAAAGTGATTATAAGATCAATCGATTTATTATATTGGTGTTGATATTTGTTACTTCAATGATATTATTAATTATTAGTCCTAATTTAATTAGTATTTTATTAGGATGAGATGGATTAGGACTTGTATCTTATTGTTTAGTTATTTATTTTCAAAATGTAAAGTCTTATAATGCTGGTATATTAACTGCATTATCTAATCGAATTGGAGATGTAGCTTTATTATTAGCTATTGCTTGAATATTAAATTATGGAAGTTGAAATTATATTTTTTATTTAGAAGTAATGAAGAATGATTTTGAAATAATAATTGTAGGAAGATTAGTAATGTTAGCTGCAATAACTAA [985]

Cebadror 9

ATGTTAAAAATTATTATTAGAATTTTATTTTTATTTCCATTATGTTTAATACATAATACTTATTGAATGGTTCAAAGTTTTT TATTTTTATTAAGTTTTATTTTTATTTTAATAAATATGTATAGAAATTATTTTATAAGAATTTCTTATTTGTTTGGATGTGATATAATTTCTTATGGATTAATTTTGTTAAGTTTATGAATTGTTTCTTTAATATTAATAGCAAGAGAATCAGTTTATAAGTATAATAATTATACAAATTTATTTTTATTAAATATTGTTTTATTATTAATTTTGTTAGTACTTACTTTTAGAAGTATAAGATTGTTTATGTTTTATTTATTTTTTGAAAGTAGTTTAATTCCAACTTTATTTTTAATTTTAGGTTGAGGATATCAACCTGAACGATTGCAAGCAGGAGTTTATTTATTATTTTATACTTTATTAGTATCTTTACCTATATTAATTGGTATTTTTTATTTATATAAGTCTACTGGTACTTTAAATTTTTATTTATTAAATAATTATATATTTAATTATGAGTTATTGTATTTTTCTTTAGTAATGGCTTTTTTAGTAAAAATACCTATGTTTTTAGTTCATTTATGATTACCTAAGGCTCATGTAGAAGCTCCTGTTTCAGGATCTATAATTTTAGCTGGAATTATATTAAAGTTAGGAGGTTATGGATTATTACGAGTATTTCCTTTTTTACAATTAATAGGATTGAAATTCAATTTTATTTGAATTAGTATTAGATTAGTAGGAGGAGTATTGGTTAGTTTAATTTGTTTACGACAAACTGATTTAAAGGCTTTAATTGCTTATTCATCAGTAGCTCATATAGGAATTGTTTTAGCTGGATTAATAACTTTAACATATATAGGAATTTGTGGTTCTTATACATTAATAATTGCTCATGGATTATGTTCTTCTGGATTATTTTGTTTAGCTAATATTTCTTATGAACGAATAGGAAGTCGTAGTTTATTAATTAATAAGGGGATATTAAATTTTATACCT-CAATAGCATTATGAT [1039]

menores variaciones entre las cepas, y presentó únicamente tres clados naciendo del nodo basal, formando una politomía. Un clado general que agrupó a las poblaciones de Brasil con la cepa de Panamá (p-95) y la de Costa Rica (CR-92). De este clado nacieron dos ramas, la primera agrupó a las cepas de Quintana Roo (CECH) y la de Oaxaca (LH). El segundo lo conformaron las cepas de Chiapas (Limón y PA-34).

El primer 8 demostró que parte del gen de tRNA presentó poca variabilidad genética en la especie $C$. hominivorax, independientemente de su procedencia, debido a ello en esta región, a diferencia de las otras dos regiones evaluadas, la población de Brasil no quedó totalmente excluida de las otras cinco cepas en estudio.

El primer 9, que amplificó principalmente la región NADH4, en el árbol filogenético presentó un nodo basal, de donde nacen dos clados bien definidos, el primero agrupando a las cepas de Oaxaca (LH) y Quintana Roo $(\mathrm{CECH})$, el segundo nace de una rama de donde nacen dos grupos, el primero formado únicamente por la población de Brasil, el segundo, de donde nuevamente nacen dos ramas, el primero formando un grupo con las cepas de Chiapas (Limón y PA-34), y el segundo grupo formado por las cepas de Panamá (P-95) y Costa Rica (CR-92). En general, este árbol filogenético mostró una evidente politomía.

Se unieron las tres regiones amplificadas, lo que abarcó completamente NADH4 - tRNA - NADH5 (Figura 1), y mostró consistencia en los resultados, formando los mismos cuatro clados que se formaron cuando se evaluaron por separado, pero con un mayor soporte, siendo estos: el primero formado por las cepas de Quintana Roo (CECH) y Oaxaca (LH) con un 100 de soporte Bayesiano, el segundo con un soporte Bayesiano de 91 con tres ramas de 


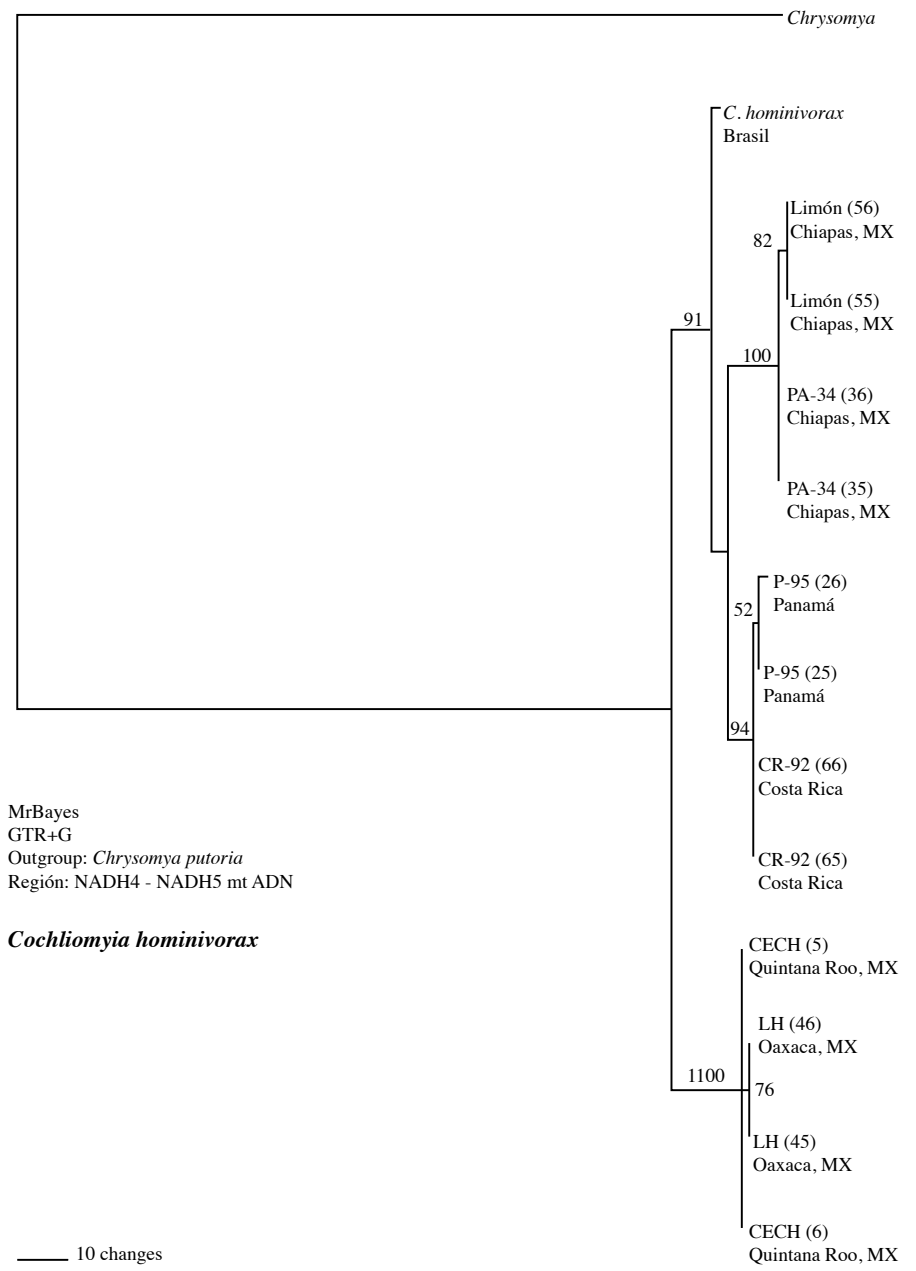

Figura 1. Dendrograma de la relación entre seis cepas del GBG Cochliomyia hominivorax procedentes de seis regiones geográficas distintas. Análisis Bayesiano de la Región del ADN mitocondrial NADH4 - NADH5 (primers 7, 8 y 9). Cepas: LH (Oaxaca, México), P-95(Gamboa, ciudad de Panamá, Panamá), CECH (Chetumal, Quintana Roo, México), PA-34 (Chiapas, México), CR-92 (Oeste de San José, Costa Rica), Limón (Palenque, Chiapas, México). Los números en las ramas del árbol representan el soporte Bayesiano.

Figure 1. Dendrogram of the relationship between six lines of GBG Cochliomyia hominivorax from six different geographical regions. Bayesian analysis of the NADH4 - NADH5 mitochondrial DNA Region (primers 7, 8 and 9). Strains: LH (Oaxaca, Mexico), P-95 (Gamboa, Panama City, Panama), CECH (Chetumal, Quintana Roo, Mexico), PA-34 (Chiapas, Mexico), CR-92 (West of San Jose, Costa Rica), Limon (Palenque, Chiapas, Mexico). The numbers on the tree branches represent the Bayesian support.

donde nacen tres grupos, el primero formado únicamente por la población de Brasil, el segundo con un soporte Bayesiano de 100, integrado por las cepas de Chiapas (Limón y PA-34) y el tercero, con un soporte Bayesiano de 94, formado por las cepas de Panamá (P-95) y Costa Rica (CR-92). 


\section{Discusión}

En las secuencias obtenidas, se pudo observar la existencia de un polimorfismo a través de los cambios que se presentaron en las bases nitrogenadas entre las cepas y los sitios en donde se dieron dichos cambios. Estos cambios son importantes, ya que son la principal fuente de información que se utilizó para realizar los análisis filogenéticos que permitieron demostrar la relación entre las cepas, tomando en cuenta que estas proceden de zonas actualmente erradicadas, las cuales fueron colectadas y reproducidas en laboratorio. El polimorfismo de las regiones estudiadas, que se ha identificado en las cepas, sugiere la presencia de distintos linajes maternales, como también fue identificado en poblaciones de Uruguay, en las regiones COX1 y COX2 del ADNmt (Fresia et al., 2007).

La región obtenida (NADH4 - tRNA - NADH5) también es un valioso aporte por ser el único reporte de esta región para C. hominivorax. La mayoría de los reportes para estas especies estan realizados en las regiones COI y COII (Lessinger et al., 2000; Mastrangelo et al., 2014). Debido a que la región de esta investigación es más grande, pudo permitir detectar mayor variabilidad entre especímenes de la misma especie.

El aporte de las secuencias de la región amplificada por los primers 8 y 9, que comprende parte de NADH4 + ARN + NADH5, aportaron información genética que permite continuar con los estudios entre las especies $C$. macellaria y C. hominivorax.

En el árbol filogenético del consenso (Figura 1), se observó una relación entre el clado formado por las dos cepas de Chiapas (Limón y PA-34) y el constituido por las cepas de Panamá (P-95) y Costa Rica (CR-92). Esto indicó una relación monofilética más cercana, y podría representar un flujo de genes desde México hasta Panamá. La relación filogenética entre las seis cepas evaluadas con la población de Brasil, presentó una relación más cercana con el clado formado por las cepas de Panamá y Costa Rica.

A pesar de las variaciones genéticas entre las distintas cepas evaluadas, los primers 7,8 y 9 , permitieron la correcta identificación de estas, siendo un aporte importante, debido a que estos primers ( 7,8 y 9) permiten identificar cepas de C. hominivorax de distintos orígenes geográficos, como México, Costa Rica y Panamá. Esta correcta identificación puede contribuir al éxito del programa de erradicación del GBG en el futuro.

Otros estudios moleculares, al emplear la restricción del genoma mitocondrial total, han mostrado variabilidad genética entre las poblaciones de Brasil, Costa Rica y México de C. hominivorax (Taylor et al., 1996). Se encontraron quince haplotipos entre cuatro poblaciones de C. hominivorax de Sao Paulo (Infante y AzeredoEspin, 1995). Estudios en siete poblaciones de C. hominivorax, procedentes de Uruguay, mostraron un alto polimorfismo y demostraron que las poblaciones de ese país formaron una panmixia (Lyra et al., 2005). A pesar de que todas estas investigaciones han sido realizadas en algunos países de América del Sur, aunque se indica alguna subestructura (McDonagh et al., 2009), no se conocen las relaciones filogenéticas de toda la región sur americana y su relación con las de Norte América, Centro América y el Caribe. En la presente investigación, el cladograma de la distribución de los haplotipos sugiere que las muestras analizadas presentan una relación monofilética muy cercana y, probablemente pertenecen a un mismo linaje evolutivo.

Una relación filogenética similar a estos resultados ha sido reportada en estudios de C. hominivorax en otras poblaciones. Se demostró que dentro de los dieciséis haplotipos encontrados se presentó una relación de parentesco entre las cepas de Oaxaca con las de Quintana Roo, mientras que las cepas de Chiapas, Costa Rica y Jamaica formaron haplotipos distintos (Roehrdanz, 1989). Otro estudio de las poblaciones de C. hominivorax, procedentes de México (Chiapas, cepa PA-34), Costa Rica, Brasil y Jamaica, demostró la existencia de un polimorfismo intraespecífico entre poblaciones (Skoda et al., 2002), por medio de la técnica RAPD-PCR. En este estudio se obtuvo un clado formado por las poblaciones procedentes de México, otro por las procedentes de Costa Rica, un tercero constituido por las poblaciones procedentes de Brasil y un último, con las poblaciones de Jamaica (Skoda 
et al., 2002). Adicional a estos clados, se demostró una relación entre la cepa de México (Chiapas, PA-34) con la de Costa Rica, aunque con un soporte de $54 \%$. Con todos estos análisis y los aportes obtenidos en la presente investigación se puede conocer parte de la biogeografía histórica de C. hominivorax, debido a sus consistencias en la formación de los clados. A pesar de la capacidad de dispersión de $C$. hominivorax, las cepas demostraron su procedencia filogenética. Un comportamiento similar de C. hominivorax estudiado por Skoda et al. (2002), se reportó en los resultados (Figura 1), donde se presentó un clado formado por las cepas de Oaxaca (LH) y Quintana Roo $(\mathrm{CECH})$, mientras las cepas de Chiapas formaron otro clado, y las cepas de Panamá y Costa Rica un tercer clado, demostrando un polimorfismo.

Para la especie C. macellaria la región de mt ADN amplificada contribuye información para estudios moleculares de la misma, debido a que existen reportes para esta especie, pero en otras regiones como: mtCOI, EF-1 $\alpha, 28$ S rRNA y la región ITS2 (Yusseff-Vanegas y Agnarsson, 2016).

\section{Conclusiones}

Existió una relación filogenética entre las cepas estudias de C. hominivorax, lo que muestra un flujo de genes desde México hasta Panamá. La región amplificada permitió detectar variaciones genéticas intraespecificas entre las cepas de $C$. hominivorax.

Las regiones amplificadas de $C$. hominivorax y $C$. macellaria aportaron información para continuar con estudios moleculares de ambas especies.

\section{Agradecimiento}

Los autores desean agradecer a ARS-USDA por proporcionar el financiamiento para poder realizar la presente investigación. A Oris Sanjur y Maribel González por su apoyo en el laboratorio de Biología Molecular del Instituto Smithsonian de Investigaciones Tropicales, Panamá.

\section{Literatura citada}

Arteaga, F.G., J.G. Rodríguez, y J.L. Olivares. 2012. Comportamiento de Cochliomyia hominivorax (Coquerel) y relación con otros agentes causantes de miasis, en un cantón de la región de manabí, Ecuador. Rev. Salud Anim. 34(1):19-24.

Becerra, V.V., and M.C. Paredes. 2000. Use of biochemical and molecular markers in genetic diversity studies. Agric. Téc. 60:270-281. doi:10.4067/S0365-28072000000300007

Cardoso G.A., C.C. Matiolli, A.M.L. De-Azeredo-Espin, and T.T. Torres. 2014. Selection and validation of reference genes for functional studies in the calliphoridae family. J. Insect Sci. 14:2. doi:10.1673/031.014.02

De-la-Ossa, N., L.E. Castro, L. Visbal, A.M. Santos, E. Díaz, y C. Romero-Vivas. 2009. Miasis cutánea por Cochliomyia hominivorax (Coquerel) (Díptera: Calliphoridae) en el Hospital Universidad del Norte, Soledad, Atlántico. Bioméd. Rev. Inst. Nac. Salud 29:12-17. doi:10.7705/biomedica.v29i1.36

Feldmann, U., and P.D. Ready. 2014. Applying GIS and population genetics for managing livestock insect pests: Case studies of tsetse and screwworm flies. Acta Trop. 138:S1-S5. doi:10.1016/j.actatropica.2014.03.025 
Ferreira-do-Nascimento, E.M., J. de-Oliveira, M. Paes, A. Lobo, A.L. Andrade-da-Silva, Rosas-dos-Santos J.E.J.L. Figueiredo, and G.E. Moya-Borja. 2005. Human myiasis by Cochliomyia hominivorax (Coquerel, 1858) (Diptera, Calliphoridae) in Recife, State of Pernambuco, Brazil. Entomol. Vector 12:37-51 doi:10.1590/S0328-03812005000100003

Fresia P., S. Lanzzeri, E. Martínez, M. Carballo, B. Goñi, J. Cristina, y S. Gama. 2007. Primer análisis de la variabilidad del ADN mitocondrial de Cochliomyia hominivorax en animales domésticos del Uruguay. Veterinaria 42(165-166):9-13.

Infante, M.E., and A.M.L. Azeredo-Espin. 1995. Genetic variability in mitochondrial DNA of the screwworm, Cochliomyia hominivirax (Dipera: Calliphoridae), from Brazil. Biochem. Genet. 33(7/8):237-256. doi:10.1007/BF02401854

Junqueira, A.C., A.C. Lessinger, T.T. Torres, F.R. da-Silva, A.L. Vettore, P. Arruda, and A.M. Azeredo. 2004. The mitochondrial genome of the blowfly Chrysomya chloropyga (Diptera: Calliphoridae). Gene 339:7-15. doi:10.1016/j.gene.2004.06.031

Lessinger, A.C., A.C. Martins-Junqueira, T.A. Lemos, E.L. Kemper, F.R. da-Silva, A.L. Vettore, P. Arruda, and A.M. AzeredoEspin. 2000. The mitochondrial genome of the primary screwworm fly Cochliomyia hominivorax (Diptera: Calliphoridae). Insect Mol. Biol. 9:521-529. doi:10.1046/j.1365-2583.2000.00215.x

Lessios, H.A., B.D. Kessing, G.M. Wellington, and A. Graybeal. 1996. Indo-Pacific echinoids in the tropical Eastern Pacific. Coral Reefs 15:133-142. doi:10.1007/BF01771904

Litjens, P., A. Lessinger, and A. Azeredo-Espin. 2001. Characterization of the screwworm flyes Cochliomyia hominivorax and Cochliomyia macellaria by PCR-RFLP of mitochondrial DNA. Med. Vet. Entomol. 15:183-188. doi:10.1046/j.13652915.2001.00289.x

Lyra, M., P. Fresia, S. Gama, J. Cristina, J. Klaczko, and A. Azeredo-Espin. 2005. Analysis of mitochondrial DNA variability and genetic, structure in populations of New World Screwworm FIies (Diptera: Calliphoridae) from Uruguay. J. Med. Entomol. 42:589-595. doi:10.1093/jmedent/42.4.589

Malliphan, S., S. Pornkulwat, J. Krumm, S. Skoda, and J. Foster. 2006. PCR - RFLP analysis of mitochondrial DNA in Screwworms (Diptera: Calliphoridae). University of Nebraska-Lincoln, NE, USA.

Mastrangelo, T., P. Fresia, M.L. Lyra, R.A. Rodrigues, and A.M. Azeredo-Espin. 2014. Genetic diversity and population structure of the New World screwworm fly from the Amazon region of Brazil. Acta Trop. 138:26-33. doi:10.1016/j. actatropica.2014.04.002

McDonagh, L., R. Garcia, and J.R. Stevens. 2009. Phylogenetic analysis of New World screwworm fly, Cochliomyia hominivorax, suggests genetic isolation of some Caribbean island populations following colonization from South America. Med. Vet. Entomol. 23:14-22. doi:10.1111/j.1365-2915.2008.00777.x

Reck, J., F.S. Marks, R.O. Rodrigues, U.A. Souza, A. Webster, R.C. Leite, J.C. Gonzales, G.M. Klafke, and J.R. Martins. 2014. Does Rhipicephalus microplus tick infestation increase the risk for myiasis caused by Cochliomyia hominivorax in cattle? Prev. Vet. Med. 113:59-62. doi:10.1016/j.prevetmed.2013.10.006

Roehrdanz, R. 1989. Intraspecific genetic variability in mitochondrial DNA of the screwworm fly (Cochliomyia hominivorax). Biochem. Genet. 27:551-569.

Skoda, S.R., P.L. Phillips, and J.B. Welch. 2018. Screwworm (Diptera: Calliphoridae) in the United States: Response to and elimination of the 2016-2017 outbreak in Florida. J. Med. Entomol. 55:777-786. doi:10.1093/jme/tjy049

Skoda, S., S. Pornkulwat, and J. Foster. 2002. Random amplified polymorphic DNA markers for discriminating Cochliomyia hominivorax from C. macellaria (Diptera: Calliphoridae). Bull. Entomol. Res. 92:89-96. doi:10.1079/BER2001135

Taylor, D.B., and E. Martínez. 1986. Genetics of the screwworm fly: Characterization of three eye mutants. J. Hered. 77:420422. doi:10.1093/oxfordjournals.jhered.a110273 
Taylor, D.B., R.D. Peterson, and G.E. Moya-Borja. 1996. Population genetics and gene variation in screwworms (Diptera: Calliphoridae) from Brazil. Biochem. Genet. 34:67-76. doi:10.1007/BF02396241

Visciarelli, E., S. García, C. Salomón, C. Jofré, and S. Costamagna. 2003. Un caso de miasis humana por Cochliomyia hominivorax (Díptera: Calliphoridae) asociado a pediculosis en Mendoza, Argentina. Parasitol. Latinoam. 58:166-168. doi:10.4067/S0717-77122003000300014

Yusseff-Vanegas S., and I. Agnarsson. 2016. Molecular phylogeny of the forensically important genus Cochliomyia (Diptera: Calliphoridae). ZooKeys 609:107-120. doi:10.3897/zookeys.609.8638 